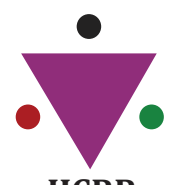

IJCRR

Section: Healthcare Sci. Journal Impact Factor: 6.1 (2018) ICV: 90.90 (2018)

\section{Scopus'}

\title{
Modern Hypolipidemic Therapy in Patients with Arterial Hypertension with High Cardiovascular Risk Under Conditions of Long-Term Ambulatory Observation
}

\author{
Ruziyeva Amira Asrorovna ${ }^{1}$, Muradova Railya Rustamovna ${ }^{2}$, \\ Turaev Khikmatulla Negmatovich², Nuralieva Rano Matyakubovna²
}

'Assistant, Department of Internal Medicine of the Pediatric Faculty with a Course of Therapy and Faculty after Graduation, Samarkand State Medical Institute, Samarkand, Uzbekistan; 'Assistant, Department of Pharmacology and Clinical Pharmacology, Samarkand State Medical Institute, Samarkand, Uzbekistan.

\section{ABSTRACT}

Globally, more human beings die from cardiovascular sickness (CVD) than from another motive. An envisioned 17.5 million humans died from CVD in 2012. Eighty \% of those deaths are because of coronary heart assaults and strokes; greater than three-quarters of all deaths occurred in low- and center-earnings countries. In 2012, 34\% of all deaths from CVD befell earlier than the age of 70 years. CVD disproportionately impacts low- and middle-earnings nations; in many nations, the financial and social burden is maximum a few of the negative and socially deprived.

Key Words: Atorvastatin, Rosuvastatin, Atherosclerosis, Hypercholesterolemia, Endothelial dysfunction, Arterial stiffness, Cardiovascular risk

\section{INTRODUCTION}

Atherosclerosis is presently the maximum not unusual pathogenic issue inside the development of severe cardiovascular pathology, which has a high frequency of fatal consequences ${ }^{1}$. Given that the diseased heart and blood vessels remain the most common cause of dying among adults in our country and other evolved countries, the prevention and remedy of atherosclerosis are the premises for lowering mortality from the pathology of the cardiovascular device ${ }^{2}$.

\section{MATERIALS AND METHODS}

Increases in blood lipids, and especially LDL cholesterol of low-density lipoproteins (HPSL), in addition to total cholesterol, triglycerides (TG) are the main causes of the improvement and progression of the atherosclerotic manner within the arterial bed. unluckily, in the Russian Federation, the prevalence within the population of expanded blood levels of cholesterol and HSLNP stays excessive and exceeds the same signs in the USA ${ }^{3}$. On this regard, the correction of blood levels of atherogenic lipids is presently considered as a fundamental factor in decreasing cardiovascular mortality.

Verification of the main parameters of the blood lipid spectrum and the need for a lipid-reducing remedy to prevent the development of atherosclerosis is executed according to the goal values of the principle lipid fractions inside the blood. The values of goal lipid tiers are decided via the diploma of risk of fatal headaches, which can be decided by the score table (for people reaching 40 years of age), and, in flip, rely upon the presence and severity of the maximum significant danger elements: systolic blood strain (SBP), gender, age, smoking and, most significantly, overall LDL cholesterol (cholesterol) within the blood (Fig. 1). The values obtained in the desk (in\%) indicate the degree of possibility of developing a fatal myocardial infarction or stroke within the subsequent 10 years in a selected individual.

\section{Corresponding Author:}

Ruziyeva Amira Asrorovna, Assistant, Department of Internal Medicine of the Pediatric Faculty with a Course of Therapy and Faculty after Graduation, Samarkand State Medical Institute, Samarkand, Uzbekistan.

ISSN: $2231-2196$ (Print)

Received: 22.04 .2020
ISSN: $0975-5241$ (Online)

Revised: 09.06 .2020
Accepted: 21.06 .2020 


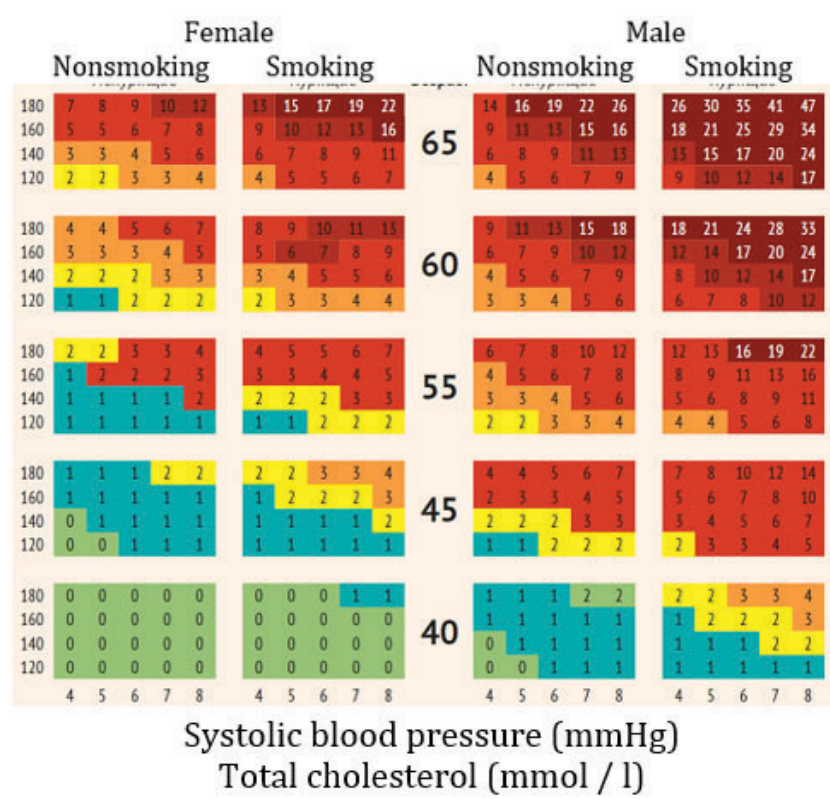

Figure 1: SCORE scale for calculating fatal cardiovascular risk.

The scale of rating - In Europe, in 2003, based totally on 12 cohort studies and information on 205178 sufferers, the score scale becomes created ${ }^{3}$. It replaced the Framingham scale inside the hints ${ }^{12}$ of the third ECU operating organization on the Prevention of Cardiovascular diseases in 2003, and its interpretation turned into adjusted inside the pointers of the 4th European operating group in $2007^{1}$.

Mainly, primarily based on the records from the cohort study of the MONICA mission, the approximate correlation among the 10-year threat of cardiovascular death and worldwide cardiovascular danger changed into modified. If within the 2003 recommendations the concept of a high hazard of cardiovascular death (5\% within the next 10 years) turned into correlated with the worldwide chance of a cardiovascular occasion $>20 \%$ (in the subsequent 10 years), then inside the 2007 pointers, the five $\%$ danger of death is already equated to $10 \%$ international threat. Although, the concept of excessive threat (as in the recommendations of 2003 described by way of the danger of demise $>$ five $\%$ in the next 10 years) endured to function a criterion for reaching the goal degree of LDL cholesterol ("awful cholesterol") $<2.5 \mathrm{mmol} / 1$. In 2007, this event significantly removed European recommendations from American ones, where the indication for such a significant reduction in cholesterol since 2002 remains the risk of non-fatal myocardial infarction or cardiac death> $20 \%{ }^{13}$.

Among 1660 patients included in the study, 27.6\% (458) were men and $72.4 \%$ (1202) women. The median age with an interquartile range was $67.8(58.8 ; 76.1)$ years. The distribution of patients by age categories is presented in Figure 2 .
Most of the patients were represented by the elderly. Among all patients included in the Register, $25.2 \%$ (419) were people aged 60 to 69 years; $31.4 \%$ (522) are people aged 70 to 79 years.

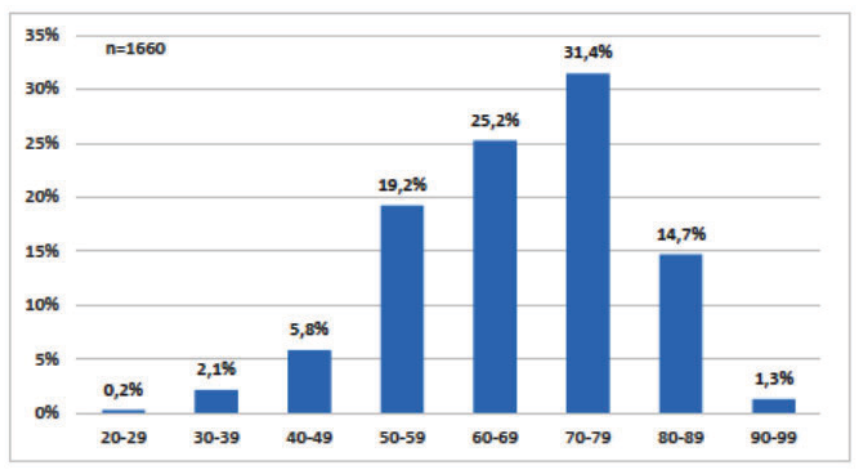

Figure 2: Distribution of patients by age categories.

The proportion of women significantly exceeds the proportion of men in all age groups, starting from the age of 50 years and older.

Example 1: To reduce the cardiovascular risk and the risk of cancer, a certain Mr. Abdullayev has $100 \mathrm{cu}$ According to a special scale; the risk of death from cardiovascular disease in Mr. Abdullayev was calculated in the next 10 years. It amounted to $8 \%$. And the risk of dying from cancer was estimated at $4 \%$. Two effective preventative interventions are available. Intervention A reduces the risk of death from a cardiovascular event by $25 \%$ relative to the absolute risk present. Intervention B reduces the risk of death from cancer by $75 \%$ relative to the absolute risk. Each intervention costs $100 \mathrm{cu}$ Due to limited funds, Mr. Abdullayev must choose one of these interventions. If he chooses intervention $\mathrm{A}$, he will reduce the risk of death from cardiovascular disease by a quarter of the risk that he had, that is, by $2 \%$. If he chooses intervention $\mathrm{B}$, he will reduce the risk of death from cancer by three-quarters of the risk that he had at the beginning, that is, by $3 \%$. This assessment shows that investing in intervention B is more effective than in intervention A. In this example, it can be seen that the assessment of cardiovascular risk in this particular person made it possible to choose the optimal method of prevention. Although there is a well-known and effective way to prevent death from cardiovascular disease, in his investing limited resources in this method is not the most effective in preventing death from any cause.

Example 2: An effective medicine is available on the market that prevents blood clotting and therefore reduces the risk of blood clots and, with regular use, reduces the risk of nonfatal myocardial infarction and cardiac death by $40 \%$ relative to the existing risk. But at the same time, this medicine gives an absolute increase in the risk of severe bleeding from the 
gastrointestinal tract and death from this bleeding by $5 \%$ in the next 10 years. According to the Framingham scale, the risk of non-fatal myocardial infarction or cardiac death in the next 10 years for Mr. Yuldashev was 10\%, and for Davidov $-20 \%$. Thus, this medicine can reduce the risk in Mr. Yuldashev by $4 \%$ and in Davidov by $8 \%$. The risk of bleeding and death from bleeding in both increases by $5 \%$. Mr. Yuldashev is more likely to develop a serious complication of taking the drug than a decrease in cardiovascular risk, and Davidov is less. Therefore, Mr. Yuldashev from this medicine will get more harm than good, and Davidov this medicine will be the best way to prevent it.

\section{RESULTS AND DISCUSSIONS}

Research results show Rosuvastin in treating the process. The results obtained in the study showed that therapy with atorvastatin led to a decrease in the content of cholesterol by $26 \%$, HPSLP by $36 \%$, TG by $24 \%$ (Table 1 ), but not to achieve the target level. The replacement of atorvastatin with rosuvastatin (Rosucard drug) was accompanied by a decrease in the level of cholesterol, cholesterol, and TG, which by the 6th month of therapy decreased by 20.53 and $8 \%$ (Table 1), respectively, and reached the target value and remained so during the subsequent therapy. The concentration of endothelin- 1 under the influence of atorvastatin therapy decreased by $45 \%$, however, the replacement of atorvastatin with rosuvastatin led to a decrease in the level of endothelin-1 by the 6 th month of therapy by another $22 \%$, by the 12 th month - by $27 \%$ (Table 2). Along with increasing the coefficient of endothelial dysfunction as a result of annual therapy with atorvastatin (12\%), therapy with rosuvastatin (Rosucard drug) allowed to increase the coefficient by another $15 \%$ by the 6 th month and by $24 \%$ by the 12 th month of treatment (Table 2). The improvement in vascular endothelial function was combined with a decrease in CRP under the influence of atorvastatin by $22 \%$ and additionally under the influence of rosuvastatin by $20 \%$ by the 6 th month, by $24 \%$ by the 12 th month.

Table 1: The level of blood lipids in patients with hypertension of high and very high cardiovascular risk during statin therapy

\begin{tabular}{|c|c|c|c|}
\hline $\begin{array}{l}\text { Significa- } \\
\text { tive }\end{array}$ & $\begin{array}{c}\text { Origi- } \\
\text { nally } \\
(\mathbf{M} \pm \mathbf{m}) \\
\mathbf{n}=114\end{array}$ & $\begin{array}{c}\text { After } 1 \text { year } \\
\text { treatment } \\
\text { atorvastatin } \\
(\mathrm{M} \pm \mathbf{m}), \mathbf{n}=114\end{array}$ & $\begin{array}{c}\text { After } 6 \text { weeks } \\
\text { treatment } \\
\text { rosuvastatin } \\
(\mathrm{M} \pm \mathrm{m}), \mathrm{n}=114\end{array}$ \\
\hline $\begin{array}{l}\mathrm{XC} \\
\mathrm{mmol} / \mathrm{l}\end{array}$ & $6,95 \pm 0,43$ & $5,15 \pm 0,32^{*}$ & $4,35 \pm 0,34$ \\
\hline $\begin{array}{l}\text { HSLNP, } \\
\text { mmol / } 1\end{array}$ & $4,74 \pm 0,21$ & $3,64 \pm 0,14^{*}$ & $2,41 \pm 0,13^{* *}$ \\
\hline HSLONP, & $1,08 \pm 0,05$ & $0,83 \pm 0,04 *$ & $0,69 \pm 0,03^{* *}$ \\
\hline
\end{tabular}

\begin{tabular}{lccc} 
HSLVP, & $0,97 \pm 0,05$ & $1,05 \pm 0,05$ & $1,21 \pm 0,05^{* *}$ \\
mmol / & & & \\
TG mmol & $2,35 \pm 0,11$ & $1,81 \pm 0,08^{*}$ & $1,52 \pm 0,08^{* *}$ \\
/ L & & & \\
\hline
\end{tabular}

\begin{tabular}{|c|c|c|}
\hline $\begin{array}{c}\text { After 12 weeks } \\
\text { treatment } \\
\text { rosuvastatin } \\
(\mathrm{M} \pm \mathrm{m}), \mathrm{n}=114\end{array}$ & $\begin{array}{c}\text { After 6 months } \\
\text { treatment } \\
\text { rosuvastatin } \\
(\mathrm{M} \pm \mathrm{m}), \mathrm{n}=\mathbf{1 1 4}\end{array}$ & $\begin{array}{c}\text { After 12 months } \\
\text { treatment } \\
\text { rosuvastatin } \\
(\mathrm{M} \pm \mathrm{m}), \mathrm{n}=114\end{array}$ \\
\hline $3,93 \pm 0,25^{* *}$ & $3,88 \pm 0,25^{* *}$ & $3,90 \pm 0,24^{* *}$ \\
\hline $1,92 \pm 0,08^{* *}$ & $1,72 \pm 0,09^{* *}$ & $1,67 \pm 0,07^{* *}$ \\
\hline $0,68 \pm 0,03^{* *}$ & $0,73 \pm 0,04$ & $0,74 \pm 0,03$ \\
\hline $1,24 \pm 0,05^{* *}$ & $1,23 \pm 0,06^{* *}$ & $1,26 \pm 0,05^{* *}$ \\
\hline $1,49 \pm 0,06^{* *}$ & $1,60 \pm 0,07^{* *}$ & $1,63 \pm 0,08$ \\
\hline
\end{tabular}

Note: * - significant difference with the initial value, $\mathrm{p}<0.05 ;$ ** - significant difference with the value after therapy with atorvastatin, $\mathrm{p}<0.05$.

Among patients who underwent determination of HDL cholesterol, $19.1 \%$ (26) had values less than or equal to 1.0 $\mathrm{mmol} / \mathrm{L}$, in $77.9 \%$ (106), the values ranged from 1.01 to 2.0 $\mathrm{mmol} / 1$, in $2.9 \%$ (4) the HDL cholesterol level exceeded $2 \mathrm{mmol} / 1$. In $73.9 \%$ (258), the TG level was less than 1.7 $\mathrm{mmol} / \mathrm{L}$, in $21.5 \%(75)$ patients the TG values were from 1.71 to $3.0 \mathrm{mmol} / \mathrm{L}, 7.4 \%$ (16) had a TG level in excess of $3.0 \mathrm{mmol} / \mathrm{L}$.

When assessing the achievement of the target values of lipid parameters depending on the risk category, it was revealed that among very high-risk patients, 54 (3.8\%) patients had a target level of OXC $\leq 4 \mathrm{mmol} / 1$, among the high-risk patients, a target level of OXC $\leq 4.5 \mathrm{mmol} / 1$ had only $1(5.6 \%)$ patient, among patients with moderate risk of the target level of total cholesterol $\leq 5 \mathrm{mmol} / 1$ reached 21 (22.1\%) patients, among patients with low risk - $13(52.0 \%)$ patients (target level of OXS $\leq 5.5 \mathrm{mmol} / 1$ ).

In $97.3 \%$ (1256) patients there was evidence of whether they were receiving lipid-lowering therapy at the time of determining the parameters of total cholesterol. The level of total cholesterol in patients not receiving lipid-lowering therapy at the time laboratory tests, amounted to $5.53(4.7 ; 6.29) \mathrm{mmol}$ $/ 1$, in patients who were at the time of the laboratory study on lipid-lowering therapy - $5.52(4.55 ; 6.39) \mathrm{mmol} / 1$, while the indicated differences were not statistically significant ( $\mathrm{p}$ $=0.72$ ).

Ultrasound duplex scanning (DDS) of the brachycephalic arteries for the entire observation period of the patient according to the outpatient data was performed in $8.55 \%$ (142) among all patients and in $7.9 \%$ (102) among patients with blood lipid levels, while these differences were not statistically significant $(p=0.52)$. There were no statistically significant differences in the frequency of ultrasound examination 
of the carotid arteries in patients with and without blood lipid data $-7.9 \%(102)$ and $10.8 \%(40)(p=0.08)$, respectively. Among all cases of carotid artery ultrasonography, in 70.4\% (100) cases, the study revealed ASB, in 21.1\% (30) - CMM thickening of more than $9 \mathrm{~mm}$, and only in $15.5 \%$ (22) cases revealed intact brachiocephalic arteries ${ }^{21}$.

\section{CONCLUSION}

1. The usage of rosuvastatin (Rosucard drug) in patients with excessive and really high SSRs who have no longer reached the target levels of atherogenic lipids due to therapy with atorvastatin, offers a lower in the stage of LDL cholesterol and HPSLP to target values.

2. The use of rosuvastatin (prepare Rosucard) is observed with the aid of a decrease inside the interest of inflammatory methods inside the vascular wall, improving the characteristic of the vascular endothelium, will increase the effectiveness of the prevention of fatal and non-fatal complications in this category of sufferers.

Acknowledgement: Authors acknowledge the immense help received from the scholars whose articles are cited and included in references of this manuscript. The authors are also grateful to authors / editors / publishers of all those articles, journals and books from where the literature for this article has been reviewed and discussed.

\section{Conflict of interest: None}

Financial support: None

\section{REFERENCES}

1. Boytsov S.A., BalanovaYu.A., Shalnova S.A. et al. Hypertension among people aged 25-64: prevalence, awareness, treatment and control. Based on the essay study. Cardiovascular therapy and prevention. - 2014 --- 4 (13). - p. 4-14.

2. Boytsov S.A., Nikulina N.N., Yakushin S.S. et al. High mortality from coronary heart disease in the Russian Federation: problems of generating statistical data (based on the results of the Russian multicenter epidemiological study of morbidity, mortality, qualitydiagnosis and treatment of acute forms of ischemic heart disease - Resonance). A heart. - 2010. - No. 1. - p.19-25.

3. Evdokimova A.G. Dyslipidemia as a risk factor for the development of cardiovascular diseases and complications. Russian Consilium Medicum. - 2009. -№10. - p. 93-99.

4. ZhilyaevaYu.A., Mikhin V.P., Gromnatsky N.I., Zhilyaeva O.A., Panchenko G.V. The state of the parameters of peroxidation of blood lipids and the elastic properties of the vascular wall inpatients with coronary heart disease during treatment with generic statins. Kursk. scientific-practical Bulletin "Man and his health." - 2013. - T. 4. - p.66-72

5. Susekov A.V. Modern approaches in the treatment of dyslipidemia: from scientific discussions to a specific patient. Medical advice. - 2015. - No. 12. - p.94-103.

6. Shalnova S.A., Oganov R.G., Deev A.D. et al. Combination of coronary heart disease with other noncommunicable diseases in the adult population: associations with age and risk factors. Cardiovascular therapy and prevention. - 2015 .-- 14 (4). - p. 44-5.

7. Murray C.J., Lopez A.D. Alternative projections of mortality and disability by cause 1990-2020: Global Burden of Daisease Study. Lancet. - 1997. - V.349. - P.1498-504.

8. Sergienko I.V., Ansheles A.A., Kukharchuk V.V. Atherosclerosis and dyslipidemia: modern aspects of pathogenesis, diagnosis and treatment. PatiSS., 2017, 128 pp. / Sergienko IV, Ansheles AA, Kukharchuk VV. Atherosclerosis and dyslipidemia: modern aspects of pathogenesis, diagnosis and treatment. PatiSS., 2017, p. 128

9. Boytsov S.A., Kalinina A.M., Ipatov P.V. Clinical examination of the adult population as a mechanism for detecting cardiovascular diseases and the formation of a dispensaryobservations. Bulletin of Roszdravnadzor, 2015,5: 9-16. / Boytsov SA, Kalinina AM, Ipatov PV. Prophylactic medical examination of the adult population as a mechanism for identifying cardiovascular diseases and establishing followup monitoring. VestnikRoszdravnadzora, 2015, 5: 9-16.

10. Shalnova S.A., Vilkov V.G., Metelskaya V.A., BalanovaYu.A., Kapustina A.V. Thirty-year dynamics of the average characteristics of blood lipids in populations of the Russian Federation and the USA. Rational pharmacotherapy in cardiUrology, 2018, 14 (1): 4-11. doi: 10.20996 / 1819-6446-2018-14-1-4-11.

11. Recommendations of the EOK / EOA for the diagnosis and treatment of dyslipidemia. European Society of Cardiology (EOK) and European Atherosclerosis (EOA) Working Group for the Diagnosis and Treatment of Dyslipidemia 2016. Russian Journal of Cardiology, 2016, 5 (145): 10-78.

12. Diagnosis and management of lipid metabolism disorders for the prevention and treatment of atherosclerosis. Russian guidelines VI revision, Moscow 2017. https://noatero.ru/sites/default/files/ references_v6.pdf.

13. Schuster $\bar{H}$, et al. Effects of switching statins on achievement of lipid goals: Measuring Effective Reductions in Cholesterol Using Rosuvastatin Therapy (MERCURY I) study. Am Heart J., 2004, 147: 705-12.

14. Jones PH, Davidson MH, Stein EA et al. for the STELLAR Study Group. Comparison of the efficacy and safety of rosuvastatin versus atorvastatin, simvastatin, and pravastatin across doses (STELLAR Trial). Am J Cardiol 2003, 92: 152-160.

15. Shalnova S.A., Deev A.D. Characterization of high-risk patients. The results of the epidemiological part of the OSCAR scientific and educational program. Cardiovascular Therapy and Prevention, 2006, 5 (5): 58-63

16. Fomin E, Baichorov I, Shikh E. Pharmacotherapy of patients with comorbidity: the possibility of drug interactions at themetabolism level. Vrach, 2014, 1: 13-17.

17. Egan A, Colman E. Weighing the benefits of high-dose simvastatin against the risk of myopathy. $\mathrm{N}$ Engl J Med, 2011, 365: 285-287.

18. Wiklund O, Pirazzi C, Romeo S. Monitoring of lipids, enzymes, and creatine kinase in patients on lipid-lowering drug therapy. Curr Cardiol Rep, 2013, 15: 397.

19. Mikhin V.P., Zhilyaeva Yu. A., Vorotyntseva V.V., Nebieridze D.V., Akhmedzhanov N.M., Vasilyeva D.A., Gromnatsky N.I. Hypolipidemic and pleotropic efficacy of Rosucard in patients with arterial hypertension with high cardiovascular risk under long-term outpatient monitoring. Russian Journal of Cardiology, 2016, 12 (140): 90-96

20. Daminova Gulbahor Oybekkizi, Igamova Dildora Nazirovna, Marg'uba Hoshimovna (2020) Increasing language skills in medical institutions. Journal of Complementary Medicine Reasearch, 11 (1), 134-138. Doi:10.5455/jcmr.2020.11.01.15 
Asrorovna et al.: Modern hypolipidemic therapy in patients with arterial hypertension with high cardiovascular risk under conditions...

21. Raunak Kotecha, Gaurav Mahajan, Saurabh Hadke, Ranjit Sidram Ambad. Management of hypertension in rural area of north-eastern region of the Maharashtra: a interventional study.
International Journal of Psychosocial Rehabilitation, Vol. 24, Issue 06, 2020. Scopus 